Risk factors and prevalence of limb deficiencies associated with amniotic band sequence : A population-based case-control study

\title{
Syvanen, Johanna
}

2021-01-01

Syvanen , J , Raitio , A , Nietosvaara , Y, Heiskanen , S , Lahdesmaa-Korpinen , A-M , Löyttyniemi , E , Gissler , M \& Helenius , I 2021 , ' Risk factors and prevalence of limb deficiencies associated with amniotic band sequence : A population-based case-control study ' , Journal of Pediatric Orthopaedics , vol. 41 , no. 1 , pp. e94-e97 . https://doi.org/10.1097/BPO.000000000000

http://hdl.handle.net/10138/338152

https://doi.org/10.1097/BPO.0000000000001686

cc_by_nc

acceptedVersion

Downloaded from Helda, University of Helsinki institutional repository.

This is an electronic reprint of the original article.

This reprint may differ from the original in pagination and typographic detail.

Please cite the original version. 


\title{
RISK FACTORS AND PREVALENCE OF LIMB DEFICIENCIES ASSOCIATED WITH AMNIOTIC BAND SEQUENCE
}

\author{
A population-based case-control study
}

Johanna Syvänen ${ }^{1}$, Arimatias Raitio ${ }^{1}$, Yrjänä Nietosvaara² ${ }^{2}$ Susanna Heiskanen ${ }^{1}$, AnnaMaria Lahesmaa-Korpinen ${ }^{4}$, Eliisa Löyttyniemi ${ }^{3}$, Mika Gissler ${ }^{4,5}$, Ilkka Helenius ${ }^{6}$

1. Department of Paediatric Surgery and Orthopaedics, University of Turku and Turku University Hospital, Turku, Finland

2. Department of Paediatric Surgery, Kuopio University Hospital, Kuopio, Finland

3. Department of Biostatistics, University of Turku and Turku University Hospital, Turku, Finland

4. Information Services Department, Finnish Institute for Health and Welfare, Helsinki, Finland

5. Department of Neurobiology, Care Sciences and Society, Karolinska Institute, Stockholm, Sweden

6. Department of Orthopaedics and Traumatology, Helsinki University Hospital and University of Helsinki, Finland

Abstract

Limb deficiencies associated with amniotic bands comprise a wide range of congenital anomalies. The association of maternal medication and the risk of amniotic band sequence 
(ABS) has not yet been addressed. Against this background we conducted a nationwide register-based case-control study. All cases with congenital limb deficiency associated with ABS born between 1996 and 2008 were included in the study. Five controls without limb deficiency matched for residency and time of conception were randomly selected from the Medical Birth Register. In total, 106 children with limb deficiency associated with ABS were identified and compared with 530 matched controls. Young maternal age $(<25$ years) increased the risk of limb deficiencies, OR $1.72(95 \% \mathrm{Cl}: 1.06,2.80)$. Nulliparity was also associated with increased risk, aOR 2.42 (95\% Cl: 1.52, 3.88). After adjusting for maternal age, pregestational diabetes, and parity, maternal use of beta blockers, aOR 24.2 (95\% Cl: 2.57 , 228) and progestogens, aOR $3.79(95 \% \mathrm{Cl}: 1.38,10.4)$ during the first trimester of pregnancy significantly increased the risk of limb deficiencies associated with amniotic bands. In conclusion, a novel association on increased risk of ABS with maternal use of progesterone or beta blockers during the first trimester of pregnancy was observed.

Keywords: Amniotic Band Syndrome; Amniotic Bands; Nulliparity; beta-Adrenergic Blockers; Progesterone; Risk Factors; Maternal Age

Word count: Abstract: 199 words - Main document: 1681 words 
Introduction

Amniotic band sequence or amniotic band syndrome (ABS) or amnion rupture sequence (ARS) is the term applied to a wide range of congenital anomalies (constriction rings associated with fibrous bands, limb and digital amputations, and cutaneous and visceral abnormalities) $(1,2)$. In the study of Lowry et al.and Bedard (2) amniotic bands with limb deficiency was the most frequent phenotype. There are two theories for the pathogenesis: the intrinsic causes (defect of germ plasm, vascular disruption and disturbance of threshold boundaries of morphogens during gastrulation) or the extrinsic causes (amniotic band rupture) $(1,3)$. The proposed pathogenesis for primary disruption of amniotic bands is that occlusion of a developing limb causes necrosis at the terminus, which adheres to and pulls off strips of amnion, resulting in mechanical damage to the fetus, such as constriction bands and clefts (4).

A population-based study from Australia reported an incidence of 2.03 per 10000 (5). This included middle trimester terminations and amniotic bands without limb deficiency. A South American group (6), on the other hand, reported birth prevalence of 0.89 per 10000 births for ADAM (amniotic deformity, adhesions, mutilations). Orioli et al. (6) also reported that $11 \%$ of their ADAM sequence cases were stillborn and 15\% died during neonatal period.

Many risk factors have been associated with amniotic band sequences with or without body wall defects. Young maternal age has been found to be associated with ARS $(4,7)$. Similarly, early reports have also identified nulliparity as a risk factor for $\operatorname{ABS}(1,4,7)$. Werler et al. (4) reported increased risk with the use of aspirin for limb reduction defects accompanied by amniotic bands. Also, the use of acetaminophen in early pregnancy has been reported to be 
a risk factor for ARS (7). To the best of our knowledge, this is the only published study to date on the association of maternal medication and the risk of ABS.

The aim of this study was to explore maternal and pregnancy related risk factors for congenital limb deficiencies associated with amniotic bands. We hypothesized that first trimester medication use would increase the risk of congenital limb deficiencies.

\section{Methods}

All cases $(n=106)$ with congenital limb deficiencies associated with amniotic bands born in Finland between Jan 1, 1996 and Dec 31, 2008 were identified from the National Register of Congenital Malformations, the Medical Birth Register and the Register on the Induced Abortions, all maintained by the Finnish Institute for Health and Welfare. Information on maternal prescription medicine use was obtained from the Register on Reimbursed Drug Purchases and the Register on Medical Special Reimbursements (Social Insurance Institution of Finland). These registers receive information based on a legally compulsory announcement request on and have been validated confirming accurate data with high coverage (8-10).

A detailed description of the data collection for congenital limb deficiencies has been given in previous papers $(11,12)$. All cases with ICD-9 codes $75 X X$ and $65 X X$ were identified and reviewed. Identified matches were checked by the principal investigators and all cases other than congenital limb deficiencies due to amniotic bands were excluded. Live births, stillbirths, and fetuses from spontaneous abortions and terminations of pregnancy due to fetal anomalies were included. 
Five controls without limb deficiencies from the Medical Birth Register matched for residency, and time of conception ( \pm 1 month) were randomly selected for each case. For the terminated fetuses, live-born, healthy_controls without congenital anomaly were selected.

Maternal risk factors in the register were analyzed including maternal age, BMI, parity, smoking, documented long-term diseases from Medical Special Reimbursements (Diabetes Mellitus, Asthma, Psychotic Mental Conditions, Depression, Epilepsy, and Inflammatory Bowel Diseases), history of miscarriages, and utilization of assisted reproductive technology (ART). Smoking was defined as active smoking during $1^{\text {st }}$ trimester. Maternal weight was recorded at the first prenatal visit 8-10 weeks after conception. The initial analysis on maternal medication was done at the $4^{\text {th }}$ level of the Anatomical Therapeutic Chemical (ATC) Classification System by WHO. Each drug group with at least five exposed mothers was studied in univariate logistic regression and significant risk factors in these analyses were included the multivariable model.

Conditional logistic regression was used to evaluate different risk factors. First, univariate models were programmed, and Fisher's exact test was executed to search potential risk factors. Subsequently, a multivariable model was created. Odds ratios (OR) along with adjusted odds ratios (aOR) with $95 \%$ confidence intervals $(\mathrm{Cl})$ were calculated. The analyses were performed using SAS System, version 9.4 for Windows (SAS Institute Inc., Cary, NC, USA).

The approval of the Institutional Review boards at the Finnish Institute of Health and Welfare and Turku University Hospital were obtained before conducting this study. 
Results

There were 106 cases of congenital limb deficiencies associated with amniotic bands including five $(4.7 \%)$ stillbirths and $38(35.8 \%)$ elective terminations of pregnancy. -Total prevalence was 1.12 per 10,000 births and live birth prevalence was 0.67 per 10,000 live births. Four infants with $A B S$ died during the first week of life and there was also one additional death during the first year of life. The perinatal mortality rate was 132 per 1,000 births and the infant mortality rate was 79 per 1,000 live births.

The 106 cases with limb deficiency associated with amniotic bands were identified and compared with 530 matched controls. In univariate analyses, young maternal age $(<25$ years, OR $1.72(95 \% \mathrm{Cl}: 1.06,2.80)$ and nulliparity OR $2.56(95 \% \mathrm{Cl}: 1.65,3.97)$, were identified as significant potential maternal risk factors for congenital limb deficiencies associated with amniotic bands. Infants with $A B S$ were more likely to be born prematurely, $O R=17.4,95 \% \mathrm{Cl}$ 9.62, 31.4. Other maternal risk factors were not significantly associated with increased risk (Table 1). Maternal illnesses were not significantly associated with increased risk of limb deficiencies.

Multivariable analysis adjusted for maternal age, nulliparity and pregestational diabetes confirmed the increased risk associated with nulliparity ( $\mathrm{aOR}=2.42,95 \% \mathrm{Cl}: 1.52,3.88)$. The multivariable analysis on maternal prescription drugs was adjusted for maternal age, nulliparity and pregestational diabetes and beta blockers (ATC code C07A) and progestogens 
(ATC code G03D) were both associated with significantly increased risk of $A B S$ (aOR $=24.2$, 95\% Cl: $2.57,228$ and aOR $=3.79,95 \% \mathrm{Cl}: 1.38,10.4$ respectively - (Table 2 ).

\section{Discussion}

In this large population-based case-control study we have demonstrated a novel finding on the increased risk of first trimester use of beta blockers and progesterone on limb deficiencies associated with amniotic bands. ABS was also associated with nulliparity and young maternal age.

Our data on exposures and outcomes were prospectively collected by the universally accessible healthcare system of our country. The registers used in this study were complete with accurate data and the coverage of the data on children with congenital limb deficiency associated with amniotic bands during the study years is high (8-13). The diagnosis of each congenital limb deficiency case associated with amniotic bands was confirmed by the principal investigators and the controversial cases were discussed by two experienced pediatric orthopedic surgeons. The case-control design was selected to identify risk factors for very rare clinical conditions.

Orioli et al. (6) reported that maternal drug use was a risk factor to ADAM sequence. We found associations with beta blockers and progesterone. This risk associated with beta blockers was 24-fold on the limb deficiencies associated with amniotic bands. There are no previous reports on associations between beta blockers and limb deficiencies. Also, an 
international cohort study found maternal beta blocker use to be safe during pregnancy with no increased risk of congenital malformations (14). In the literature there are reports of maternal pre-eclampsia and chronic hypertension in patients with limb deficiencies (15-17). Our findings on the beta blockers support the hypothesis that amniotic band syndrome associated limb deficiency might be related to changes in the fetal microvascular system (4).

Current data showed an association with progestogens and limb deficiencies associated with amniotic bands. There are early reports on maternal use of exogenous sex hormones and associations of various congenital malformations including $\operatorname{limb}$ deficiencies (18-20). Other reports have not found significant associations (21). Recent prospective observational cohort study found no association between major birth defects and oral contraceptives (22). Most cases in our research had natural progestogens code which is often used with ART. Based on our research it is impossible to say if it is the hormone itself, the technology used, or the maternal and paternal factors related to subfertility that cause the positive correlation with congenital limb deficiencies. Previous studies have also had the same challenge (23).

Several studies have reported a positive association with active smoking and amniotic band sequence-limb-body-wall-complex $(\operatorname{ABS}-\operatorname{LBWC})(4,24,25)$ and one study found significant positive association with secondhand smoking (26). Our results also suggested that smoking would be associated with increased risk, but the association was not statistically significant. Also, our study was limited by lacking data on maternal smoking in the Register of Induced Abortions. 
Previous studies have reported twofold increase in the risk of ABS associated with young maternal age $(5,27)$. Werler et al. (7) observed a threefold increase in ABS among mothers $<25$ years of age. However, this association was not statistically significant. Similar, borderline significant results were also reported by Orioli et al. (6) Our findings support previous results regarding young maternal age as a risk factor for ABS.

Our results were consistent with early reports regarding the increased risk of limb deficiencies associated with amniotic bands among nulliparous women $(1,4,7)$. Besides $A B S$, nulliparity has been previously identified as a risk factor for several other birth defects including diaphragmatic hernia, omphalocele, and gastroschisis (28). It has been postulated, that biologic or environmental factors associated with nulliparity could explain these associations. However, the underlying mechanism remains unclear (28).

In conclusion, a novel finding on the increased risk of ABS associated with maternal use of progestogens and beta blockers was observed. Future studies are warranted to confirm these associations. Early reports on the increased risk of ABS associated with nulliparity and young maternal age were supported by our results.

\section{Acknowledgements}

This work was supported by grants from Clinical Research Institute HUCH received by Dr Raitio, Dr Syvänen, and Pprof Helenius. Also, we would like to thank Drugs and Pregnancy muotoili: Fontti: $12 \mathrm{pt}$ project for their co-operation with this study. 


\section{Conflict of Interest}

None 
1. Cignini P, Giorlandino C, Padula F, et al. Epidemiology and risk factors of amniotic band syndrome, or ADAM sequence. J Prenat Med 2012;6(4):59-63.

2. Lowry RB, Bedard T, Sibbald B. The prevalence of amnion rupture sequence, limb body wall defects and body wall defects in Alberta 1980-2012 with a review of risk factors and familial cases. American Journal of Medical Genetics Part A 2017;173(2):299-308.

3. Torpin R. Amniochorionic Mesoblastic Fibrous Strings and Amnionic Bands: Associated Constricting Fetal Malformations or Fetal Death. Am J Obstet Gynecol 1965;91:65-75.

4. Werler MM, Bosco JLF, Shapira SK. Maternal vasoactive exposures, amniotic bands, and terminal transverse limb defects. Birth Defects Research Part A, Clinical and Molecular Teratology 2009;85(1):52-7.

5. Bower C, Norwood F, Knowles S, et al. Amniotic band syndrome: a population-based study in two Australian states. Paediatr Perinat Epidemiol 1993;7(4):395-403.

6. Orioli IM, Ribeiro MG, Castilla EE. Clinical and epidemiological studies of amniotic deformity, adhesion, and mutilation (ADAM) sequence in a South American (ECLAMC) population. Am J Med Genet A 2003;118A(2):135-45.

7. Werler MM, Louik C, Mitchell AA. Epidemiologic analysis of maternal factors and amniotic band defects. Birth Defects Res A Clin Mol Teratol 2003;67(1):68-72.

8. Gissler M, Teperi J, Hemminki E, et al. Data quality after restructuring a national medical registry. Scand J Soc Med 1995;23(1):75-80.

9. Pakkasjärvi N, Ritvanen A, Herva R, et al. Lethal congenital contracture syndrome (LCCS) and other lethal arthrogryposes in Finland--an epidemiological study. American Journal of Medical Genetics Part A 2006;140A(17):1834-9.

10. Leoncini E, Botto LD, Cocchi G, et al. How valid are the rates of Down syndrome internationally? Findings from the International Clearinghouse for Birth Defects Surveillance and Research. American Journal of Medical Genetics Part A 2010;152A(7):1670-80.

11. Koskimies $\mathrm{E}$, Lindfors $\mathrm{N}$, Gissler $\mathrm{M}$, et al. Congenital upper limb deficiencies and associated malformations in Finland: a population-based study. The Journal of Hand Surgery 2011;36(6):1058-65.

12. Syvänen J, Nietosvaara Y, Ritvanen A, et al. High risk for major nonlimb anomalies associated with lower-limb deficiency: a population-based study. The Journal of bone and joint surgeryAmerican volume 2014;96(22):1898-904.

13. KELA. The Social Insurance Institution of Finland.

14. Bateman BT, Heide-Jorgensen U, Einarsdottir K, et al. beta-Blocker Use in Pregnancy and the Risk for Congenital Malformations: An International Cohort Study. Ann Intern Med 2018;169(10):665-73.

15. Rogala EJ, Wynne-Davies R, Littlejohn A, et al. Congenital limb anomalies:frequency and aetiological factors. Data from the Edinburgh Register of the Newborn (1964-68). Journal of Medical Genetics 1974;11(3):221-33.

16. Polednak AP, Janerich DT. Maternal factors in congenital limb-reduction defects. Teratology 1985;32(1):41-50.

17. Bellizzi S, Ali MM, Abalos E, et al. Are hypertensive disorders in pregnancy associated with congenital malformations in offspring? Evidence from the WHO Multicountry cross sectional survey on maternal and newborn health. BMC pregnancy and childbirth 2016;16(1):198

18. Janerich DT, Piper JM, Glebatis DM. Oral contraceptives and congenital limb-reduction defects. The New England Journal of Medicine 1974;291(14):697-700.

19. Heinonen OP, Slone D, Monson RR, et al. Cardiovascular birth defects and antenatal exposure to female sex hormones. The New England Journal of Medicine 1977;296(2):67-70. 
20. Czeizel A, Keller S, Bod M. An aetiological evaluation of increased occurrence of congenital limb reduction abnormalities in Hungary, 1975-1978. International Journal of Epidemiology 1983;12(4):445-9.

21. Lammer EJ, Cordero JF. Exogenous sex hormone exposure and the risk for major malformations. JAMA 1986;255(22):3128-32.

22. Charlton BM, Mølgaard-Nielsen D, Svanström H, et al. Maternal use of oral contraceptives and risk of birth defects in Denmark: prospective, nationwide cohort study. BMJ (Clinical research ed) 2016;352:h6712.

23. Berntsen S, Söderström-Anttila V, Wennerholm U-B, et al. The health of children conceived by ART: 'the chicken or the egg?'. Human Reproduction Update 2019;25(2):137-58.

24. Czeizel AE, Vitez $\mathrm{M}$, Kodaj I, et al. Study of isolated apparent amniogenic limb deficiency in Hungary, 1975-1984. Am J Med Genet 1993;46(4):372-8.

25. Wasserman $\mathrm{CR}$, Shaw $\mathrm{GM}, \mathrm{O}$ 'Malley $\mathrm{CD}$, et al. Parental cigarette smoking and risk for congenital anomalies of the heart, neural tube, or limb. Teratology 1996;53(4):261-7.

26. Hoyt AT, Canfield MA, Romitti PA, et al. Associations between maternal periconceptional exposure to secondhand tobacco smoke and major birth defects. Am J Obstet Gynecol 2016;215(5):613 e1- e11.

27. Gill SK, Broussard C, Devine O, et al. Association between maternal age and birth defects of unknown etiology: United States, 1997-2007. Birth Defects Res A Clin Mol Teratol 2012;94(12):1010-8.

28. Duong HT, Hoyt AT, Carmichael SL, et al. Is maternal parity an independent risk factor for birth defects? Birth Defects Research Part A, Clinical and Molecular Teratology 2012;94(4):230-6. 
Table 1. Maternal risk factors for congenital limb deficiencies associated with amniotic bands.

\begin{tabular}{lcccc}
\hline & \multicolumn{2}{c}{ Number of Events } & $\begin{array}{c}\text { Odds } \\
\text { ratio }\end{array}$ & $\mathbf{9 5 \%} \mathbf{C l}$ \\
\cline { 2 - 4 } & $\begin{array}{c}\text { Cases } \\
(\mathbf{n}=\mathbf{1 0 6})\end{array}$ & $\begin{array}{c}\text { Controls } \\
(\mathbf{n}=\mathbf{5 3 0})\end{array}$ & & \\
\hline Maternal Age < 25 years (ref 25 - 34) & $33(31.1 \%)$ & $111(20.9 \%)$ & 1.72 & $1.06,2.80$ \\
Maternal Age $\geq \mathbf{3 5}$ years (ref 25 - 34) & $11(10.4 \%)$ & $67(12.6 \%)$ & 0.92 & $0.45,1.86$ \\
Nulliparity & $70(66.0 \%)$ & $228(43.0 \%)$ & 2.42 & $1.52,3.88$ \\
Pregestational diabetes & $2(1.9 \%)$ & $2(0.4 \%)$ & 5.08 & $0.71,36.5$ \\
Maternal chronic hypertension & $2(1.9 \%)$ & $2(0.4 \%)$ & 10.2 & $0.91,113.6$ \\
ART & $3(2.8 \%)$ & $11(2.1 \%)$ & 2.50 & $0.63,10.0$ \\
Smoking & $18(17.0 \%)$ & $90(17.0 \%)$ & 1.61 & $0.88,2.94$ \\
Multiple pregnancy & $4(3.8 \%)$ & $22(4.2 \%)$ & 0.91 & $0.31,2.67$ \\
Invasive fetal investigation & $4(3.8 \%)$ & $18(3.4 \%)$ & 1.46 & $0.46,4.57$ \\
Prematurity & $59(55.7 \%)$ & $33(6.2 \%)$ & 17.4 & $9.62,31.4$ \\
Male Sex & $52(49.1 \%)$ & $260(49.1 \%)$ & 1.03 & $0.67,1.58$ \\
\hline
\end{tabular}


Table 2. Multivariable analysis of maternal risk factors for congenital limb deficiencies associated with amniotic bands.

\begin{tabular}{|c|c|c|c|c|}
\hline \multirow{2}{*}{$\begin{array}{l}\text { Exposure } \\
\text { (ATC code) }\end{array}$} & \multicolumn{2}{|c|}{ Number of Events } & \multirow{2}{*}{$\begin{array}{l}\text { Adjusted } \\
\text { Odds ratio }\end{array}$} & \multirow[t]{2}{*}{$95 \% \mathrm{Cl}$} \\
\hline & $\begin{array}{c}\text { Cases } \\
(n=106)\end{array}$ & $\begin{array}{l}\text { Controls } \\
(n=530)\end{array}$ & & \\
\hline Beta blockers (C07A) & $4(3.8 \%)$ & $1(0.2 \%)$ & 24.2 & $2.57,228.2$ \\
\hline Progestogens (G03D) & $7(6.6 \%)$ & $11(2.1 \%)$ & 3.79 & $1.38,10.4$ \\
\hline Gonadotropins (G03G) & $3(2.8 \%)$ & $11(2.1 \%)$ & 1.46 & $0.39,5.45$ \\
\hline Muscle relaxants (M03B) & $2(1.9 \%)$ & $3(0.6 \%)$ & 4.39 & $0.36,53.1$ \\
\hline
\end{tabular}

